INDEPENDENT JOURNAL OF MANAGEMENT \& PRODUCTION (IJM\&P)

http://www.ijmp.jor.br

v. 12, n. 8, November-December 2021

ISSN: 2236-269X

DOI: 10.14807/ijmp.v12i8.958

\title{
ABOUT BIOLOGICAL HIP JOINT PROSTHESES AND THE BIOMECHANICAL BEHAVIOR OF IMPLANTED FEMUR
}

\author{
Raffaella Aversa \\ Advanced Materials Lab, Department of Architecture and Industrial \\ Design, Second University of Naples, Italy \\ E-mail: raffaella.aversa@unina2.it \\ Relly Victoria Virgil Petrescu \\ IFToMM, Romania \\ E-mail: rvvpetrescu@gmail.com
}

Antonio Apicella

Advanced Materials Lab, Department of Architecture and Industrial Design, Second University of Naples, Italy

E-mail: antonio.apicella@unina2.it

Florian Ion Tiberiu Petrescu

IFToMM, Romania

E-mail: fitpetrescu@gmail.com

Submission: $1 / 6 / 2019$

Revision: $11 / 24 / 2020$

Accept: 12/1/2020

\section{ABSTRACT}

Biofidel femur Models with finite elements were developed using a specific segmentation combination with computed tomography and solid modeling tools capable of representing bone physiology and structural behavior. These biofidel Finite Element Models (FEM) are used to evaluate the change in the physiological distribution of stress in the prosthesis femur and to evaluate the new design criteria for biopsy biopsy biopsy biopsy. The proposed belief patterns allowed us to adequately take into account the non-isotropic features of the proximal femoral epiphysis and isotropic behavior in diaphysis to explain the critical changes in stress distribution in a femur resected after the implantation of a traditional articular prosthesis. It has been shown that a wide range of femoral diaphyses is completely protected by rigid prostheses that significantly alter the physiological distribution of stress, which should guarantee healthy growth and bone regeneration.

Keywords: Biotechnology; Bioengineering; Biomaterials; Trabecular bone; Biomimetic; Biomechanics; Trabecular prostheses 
DOI: 10.14807/ijmp.v12i8.958

\section{INTRODUCTION}

A highly interdisciplinary research group has been involved in the study of bone as a living material. The principal efforts have been devoted to mimic the bone characteristics and a process of its formations and behavior under physiological loading (Apicella et al., 20102011, 2015; Gramanzini et al., 2016; Kummer, 1986; Perillo et al., 2010; Sorrentino et al., 2009, 2007).

Advanced academic studies on biomechanics and biomimetic of implanted bones resulted from these investigations. This work project identifies a number of design criteria to foster their potential to enable new medical therapies contributing to customized health care and to create and improve the technological basis for innovative prostheses design.

The human femur is characterized by a specific internal structure (Oh \& Harris, 1976; Gottesman \& Hashin, 1980) that imparts to the bone a high capacity to withstand external stresses while optimizing its mass distribution and morphology (Ashman et al., 1984; Dalstyra et al., 1993). However, physiological bone mass loss progressively occurs at an older age, reducing its toughness and capability to dissipate the energy transmitted by external shock event, and this feature is the cause of most of the elder people pertrochanteric fractures along the plane indicated in figure 1.

Aversa et al. (2016) have successfully modeled this behavior. Pertrochanteric fractures need hip joint prosthesis application (Ashman \& Rho, 1988, Burnstein et al., 1976, Carter \& Hayes, 1977).

The modification of the biomechanical behavior of aged or implanted bones can be correctly predicted using our previously developed biofidel Finite Element Modeling (FEM).

However, replacement of the total hip in patients under the age of 65 years and therefore the required prolonged durability of the orthopedic implant may not take more than 15 years. However, this clinical scenario is changing now. More technological developments in health have increased life expectancy. In addition, the prognosis of physical trauma caused by sports, excessive exercise and excessive exercise or road accidents has improved. The new design then requires durable and biomechanically compatible prostheses.

The orthopedic prostheses used today are made of metal alloys, plastics, and ceramics with well-defined properties and characteristics. Especially due to the biocompatibility of their high mechanical strength and commonly used metal alloys, they are based on cobalt, titanium 
INDEPENDENT JOURNAL OF MANAGEMENT \& PRODUCTION (IJM\&P)

http://www.ijmp.jor.br

v. 12, n. 8, November-December 2021

ISSN: 2236-269X

DOI: 10.14807/ijmp.v12i8.958

or chromium and represent almost all the prosthetic components that are in direct contact with the human bone, as they could provide optimal bones for integration.

Implant failures are mainly due to incompatibility between a prosthesis and bone biomechanics, inadequate strength or rigidity, which is an inadequate bone for the implant, causing bone discontinuities in the distribution of stress and biological strains. Current implants (metallic and ceramic) that are more rigid than bone, physiological changes in strong blood distribution, and prevent the transfer of stress to the adjacent bone (Apicella et al., 2010, 2011, 2015) to loosen the implant.

To predict structural changes induced by the modification of bone morphological and mechanical characteristics, femoral models have been developed (Aversa et al., 2016). The development of these bio-models has already allowed us to predict strictly the physiological stress and strain distribution in mandibular and prosthetic implants (Apicella et al 2010, Gramanzini et al., 2016, Perillo et al., Sorrentino et al 2009, 2007).

This paper developed a femoral FEM model elaborated in a previous paper, which is the correct structural behavior of the femur head (Aversa et al., 2016) for the distribution of stress and tension on the stem and head and was modified to take account of resection of the femoral head and replacement with a Titan hip prosthesis for the femoral fracture (Figure 1). A comparison of the biologic stress and strain distribution in the femoral neck and the femoral femur could help to understand the correct design procedures needed to design new innovative biomimetic prostheses (Annunziata et al., 2006, 2008; Apicella et al., 2010; 2011, 2015; Aversa et al., 2009, 2016a-o, 2017; Beaupre \& Hayes, 1985; Bonfield et al., 1981; Comerun, 1986; Čepelak, 2013; Chen, 2013; Cormack, 2012; Davis et al., 1991; Dechow 2003; Filmon et al., 2002; Frost, 1964,1990, 2004; Gorustovich et al., 2010; Gramazzini et al., 2016; Halpin \& Kardos, 1976; Heinemann et al., 2013; Hutmacher, 2000; Hoppe et al., 2011; Hench \& Wilson, 1993; Hench \& Polak, 2002; Hench \& Thompson, 2010; Huiskes et al., 1987; Julien et al., 2007; Jones \& Clare, 2012; Kim et al., 2004; Karageorgiou \& Kaplan, 2005; Kabra et al., 1991; Mano et al., 2004; Mirsayar et al., 2017; Morales-Hernandez et al., 2012; Mouriño et al., 2012; Montheard et al., 1992; Petrescu, 2018; Petrescu \& Calautit, 2016a-b; Petrescu et al., 2015, 2016a-e, 2017, 2018; Perillo et al., 2010; Peluso et al., 1997; Prashantha et al., 2001; Reilly \& Burnstain, 1974, 1975; Schiraldi et al 2004; Schwartz-Dabney \& Dechow, 2003; Sorrentino et al., 2007, 2009; Töyräsa et al., 2001; Wolff, 1892). 


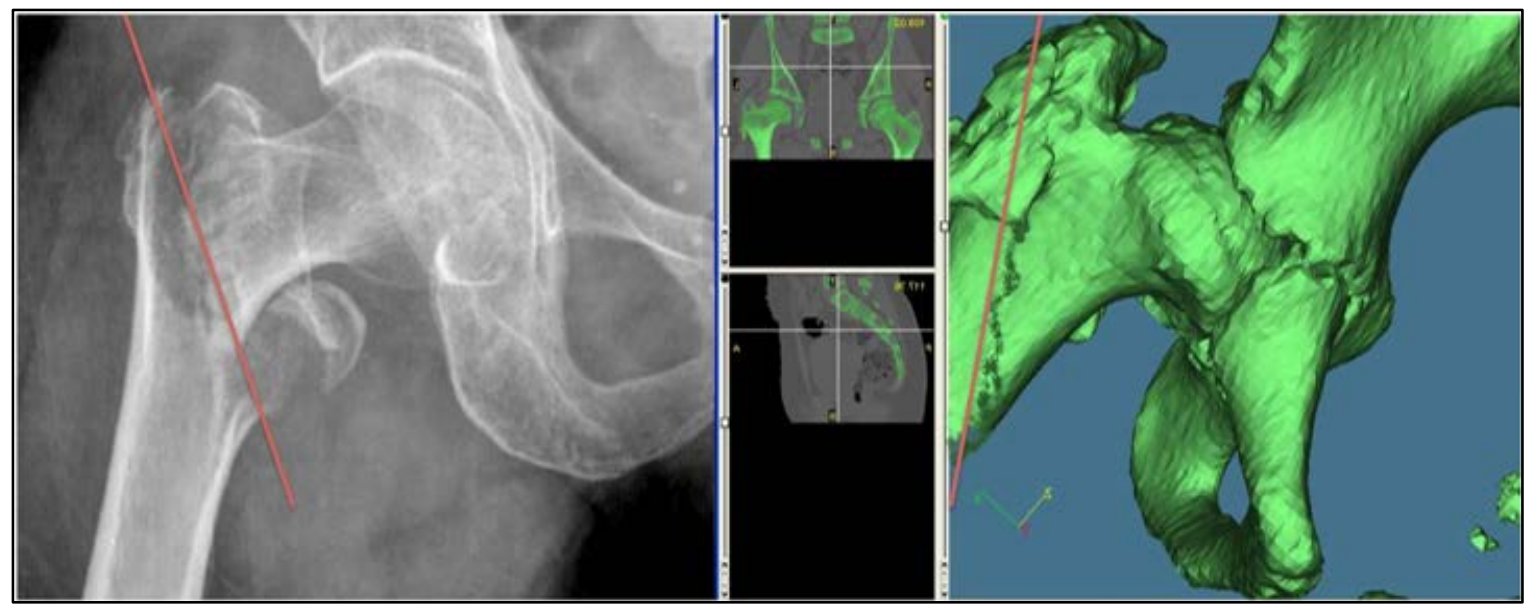

Figure 1: Fracture planes (red line) of a pertrochanteric femur fracture (left CT) and solid modeling from software for CT segmentation in the proximal epiphysis - pelvis region.

\section{METHODS AND MATERIALS}

The CT-derived segmentation was performed using the Mimics software (Materialize, Belgium) to process the patient's CT.

Solid anatomic solid and femoral pelvis, see Figure 2, were obtained by processing CT data.

New prosthetic models using the combined use of the Mimics and 3-Matic software (Materialize, Belgium) can be obtained from the biomechanical study of these bone marrow.

The combined model of solid modeling and finite element analysis was developed in a previous work by Aversa et al. (2016).

These methods simulate the structural morphology of the femur as has already been done for other complex bone structures that take into account the trabecular bone orientation and densities (Apicella et al., 2010, 2011, 2015, Aversa et al., 2016, Aversa et al. 2009, Beaupre et al., 1985; Reilly \& Burstein 1974; Reilly \& Burstein 1975; Huiskes et al., 1987; Taylor et al., 2007, Rohlmann et al., 1982). Several recent studies have highlighted the importance of FEM analysis in clinical applications and the development of new prosthetic systems (Mirsayar \& Park 2016, Mazaheri et al., 2016) and the use of innovative materials and surface treatments (Kumar et al., 2016). 


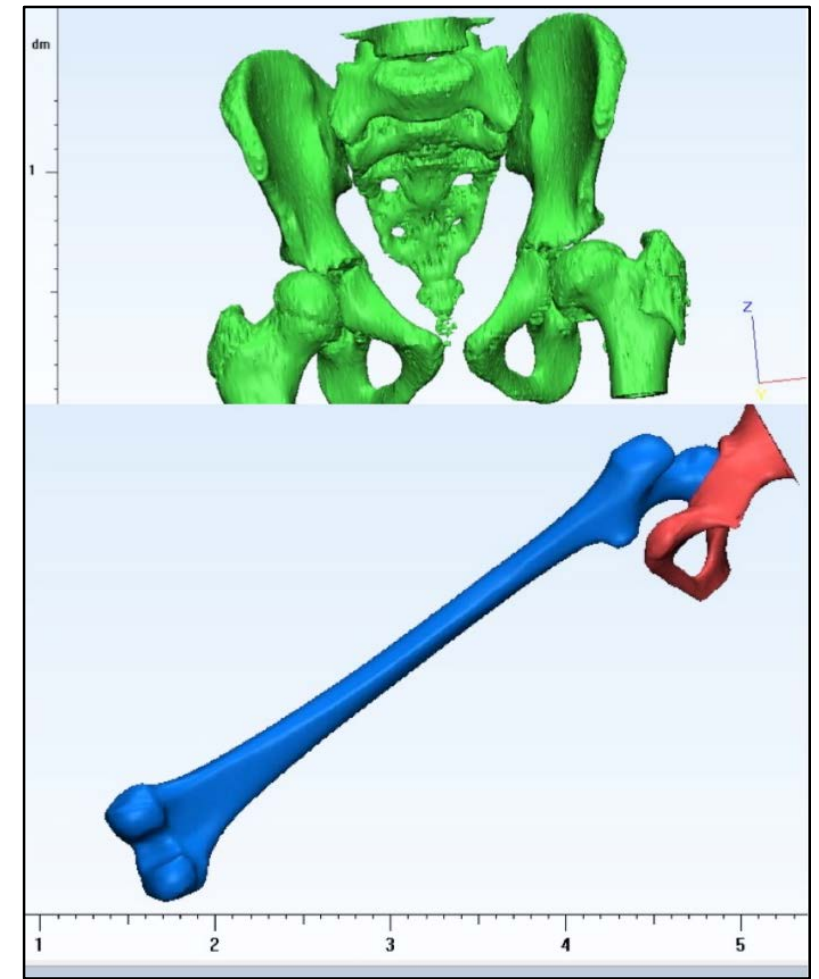

Figure 2: Biofidel medical Image Segmentation of a patient pelvis and femur.

The methodological procedure is illustrated in the Figures from 3 to 6 . The external geometry of femur and portion of the pelvis have been remodeled creating a 3D volume from the CT scans (Figure 3).

The models were imported in the 3Matic software in order to create and optimize surface and solid meshing, which was needed to the preparation of the Finite element model and for the designation of material properties (Aversa et al., 2016).

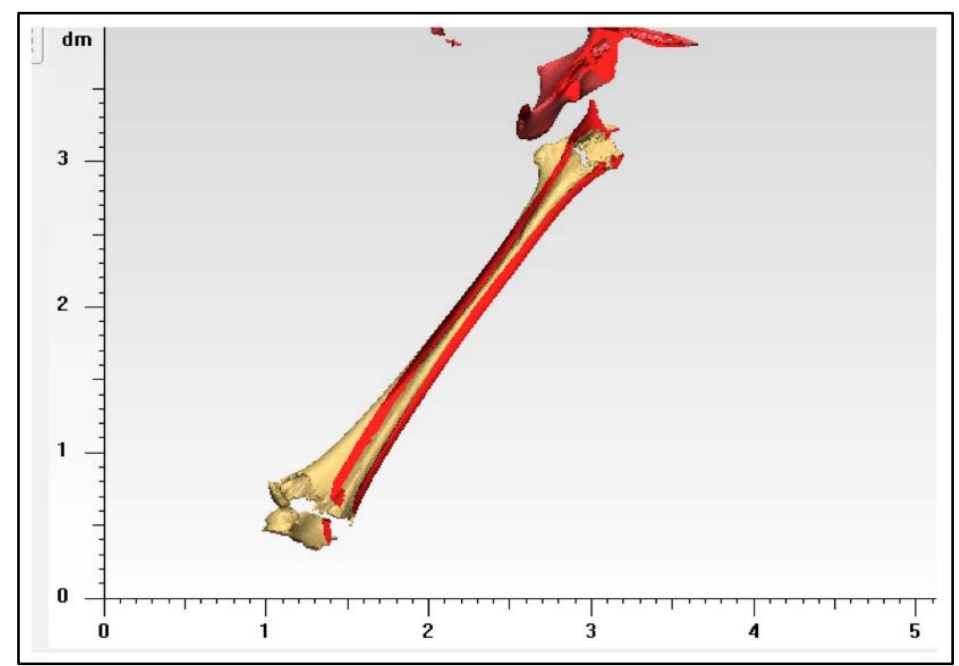

Figure 3: Biofidel 3D solid modelling of a patient femur and pelvis 
DOI: 10.14807/ijmp.v12i8.958

The results of tethra-edric element material distribution are shown in Figure4.

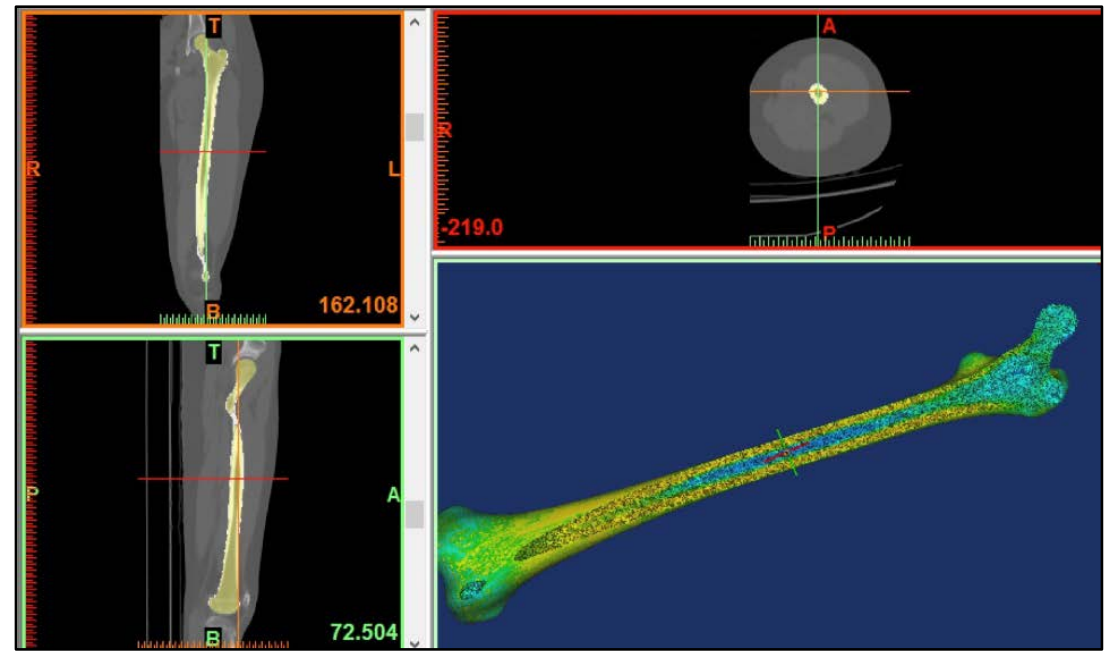

Figure 4: Mesh creation and optimization of the biofidel not resected femur model Source: Aversa et al. (2016)

The same procedure has been applied to the preparation of the FEA model of the femur with the resection of the head (Figure 5), which has been virtually related to the fracture plane reported in figure 1, and for the Titanium traditional hip-joint prosthesis (reported in the Left side of Figure 6).

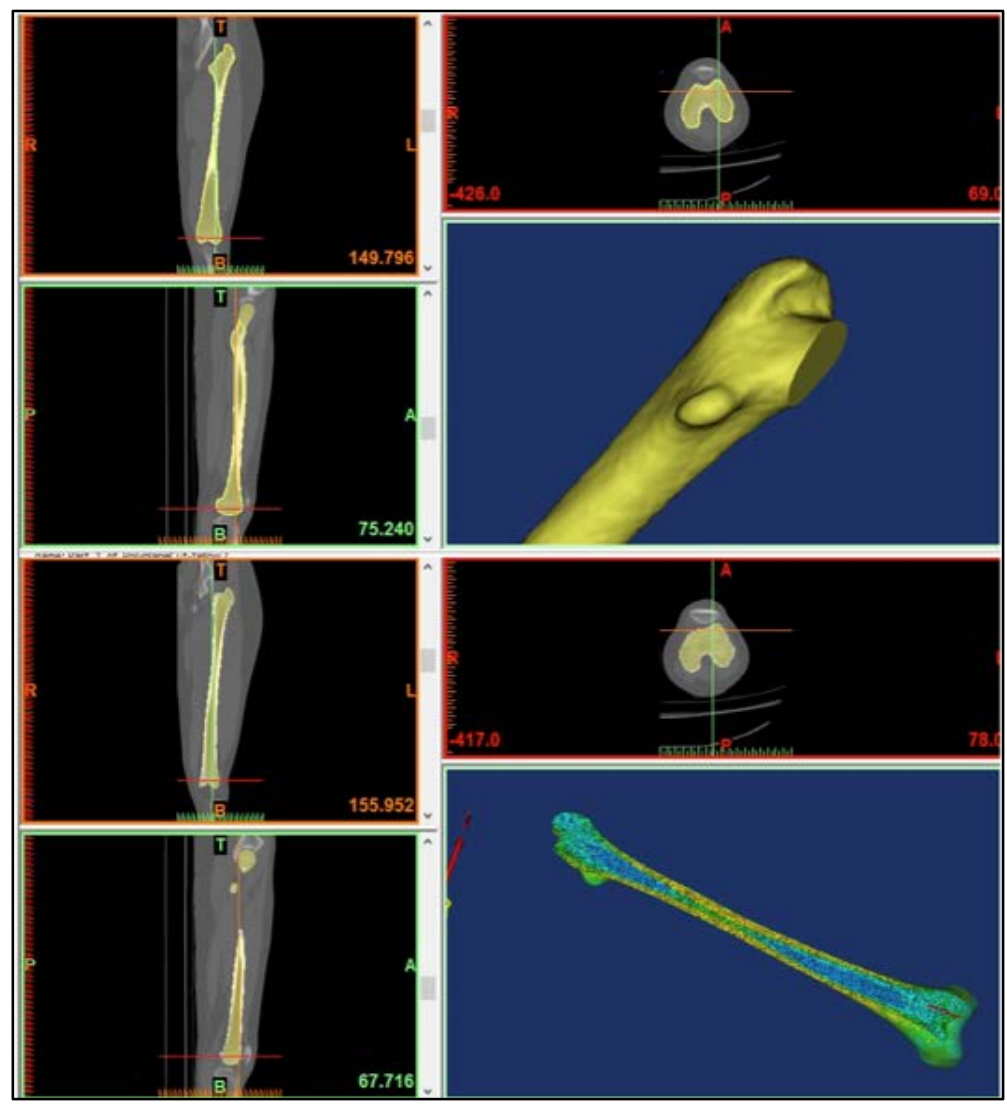

Figure 5: 3D meshing optimization of the biofidel patient femur model 
DOI: $10.14807 /$ ijmp.v12i8.958

The model of the resected femur and of the Titanium prosthesis has been realized by definition of the 3D tethraedric mesh optimization of the distribution and size, as indicated in the right side of Figure 5 and in Figure 6, respectively.

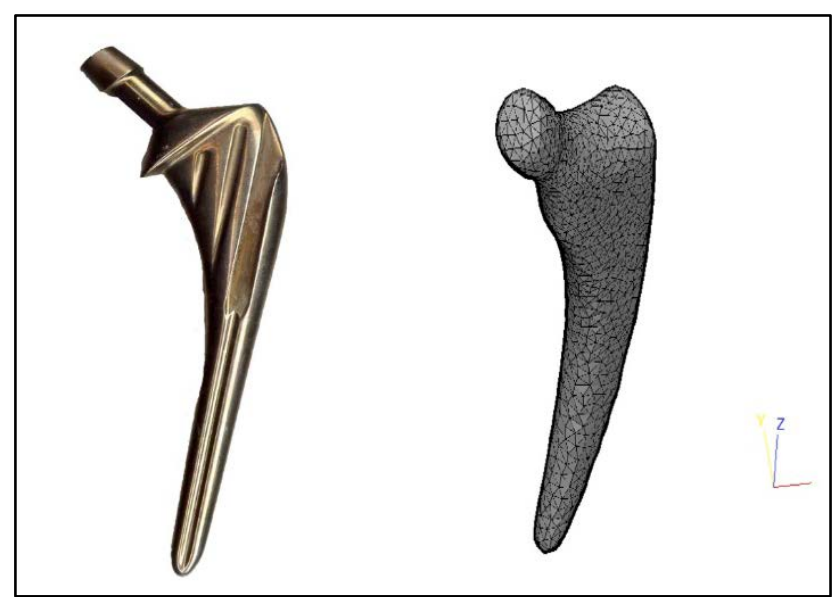

Figure 6: 3D meshing optimization of a Titanium traditional prosthesis

The solid mesh elements of the resected femur have been associated to the bone densities such as measured by a Hounsfield (HU) scale, which compute the X-rays linear attenuation coefficients of in the tissues, by the Mimics software (lower part of Figure 5). The meshed solid models of the resected femur and of the Ti prosthesis were assembled accounting to the correct positioning of the implant using the Mimics software (figure 7).

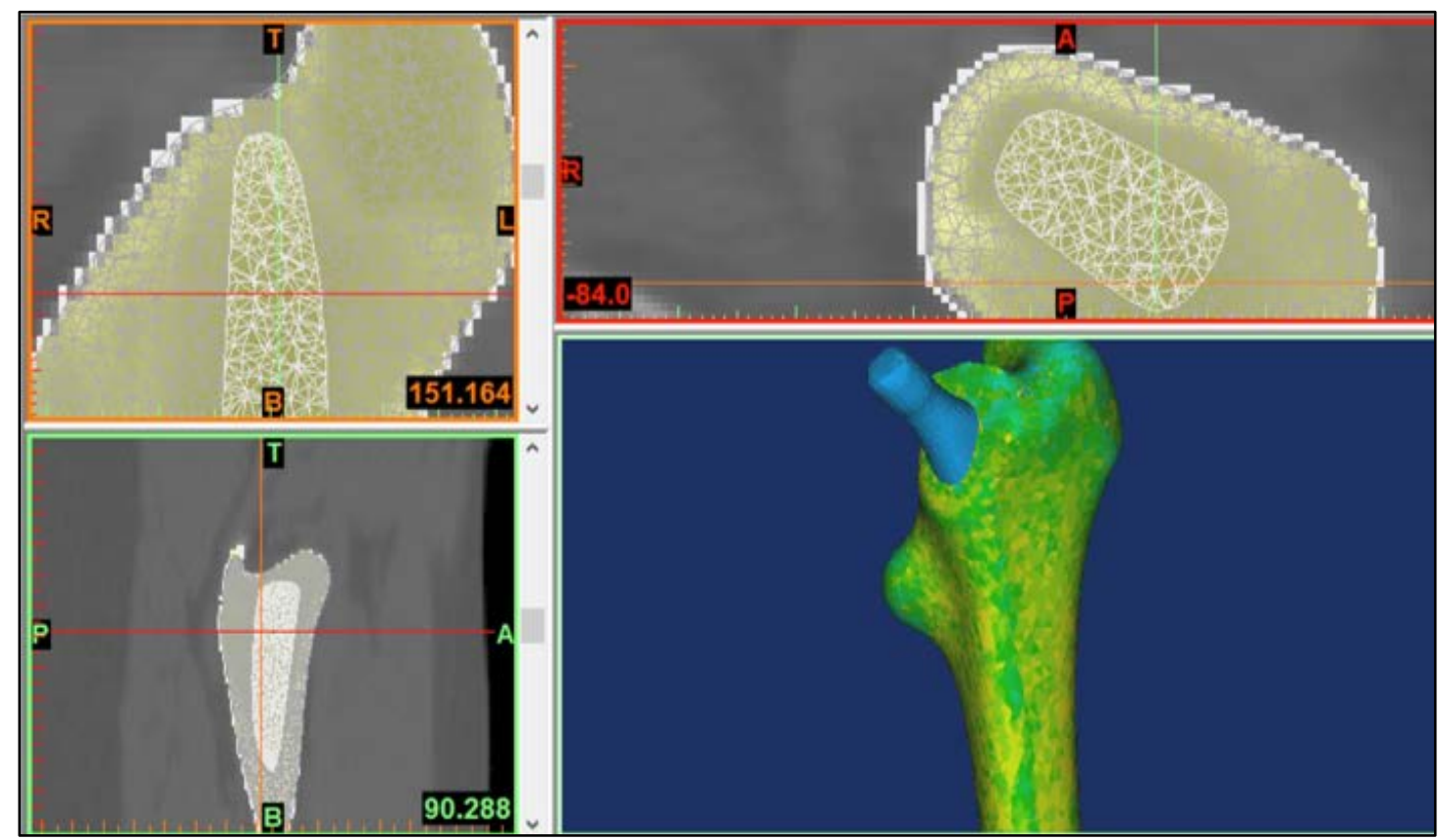

Figure 7: Assembly and material properties definition associated to the patient femur cortical and trabecular bone densities and to the Titanium prosthesis 
DOI: 10.14807/ijmp.v12i8.958

New remeshing of the tethraedric elements were run in 3Matic (figure 8) searching for the node congruency at the bone-implant interfaces, where the material definition has been made for the new finite elements configuration. The evaluation of mechanical properties has been done considering the cortical and trabecular bone mechanical characteristics.

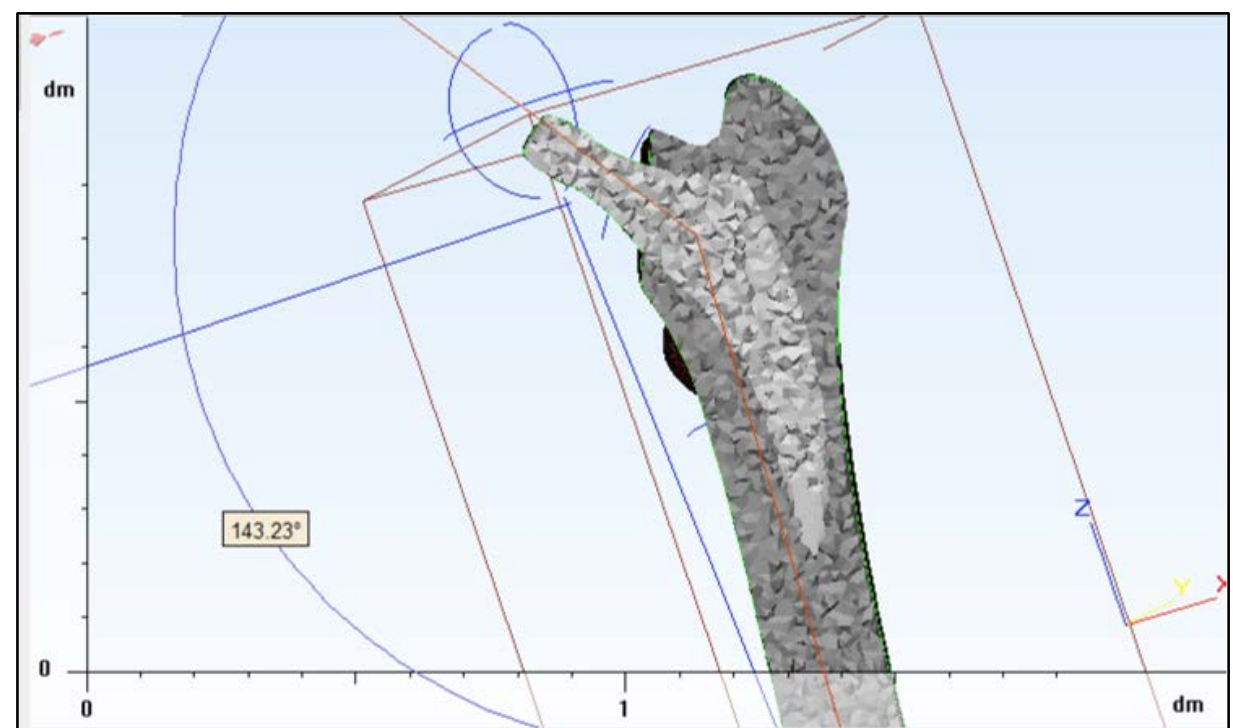

Figure 8: Assembly of the resected femur and Titanium rigid hip prosthesis and tethraedric mesh congruency verification

In the Hounsfield (HU) scale, the trabecular bone is in the range 100-300, while the cortical bone covers values from 200 up to about 2000, which corresponded in our bone systems to Elastic moduli ranging from 0,87 to $15.0 \mathrm{GPa}$. The fat value is about -110 , the muscle about 40. Finally, the mechanical properties of the prosthesis Ti alloy are: elastic modulus equals $124 \mathrm{GPa}$ and Poisson ratio 0.3.

\section{FEM analysis: sound and prosthesis femur}

On the basis of the 3D models of the sound femur, and the resected femurs implanted with a traditional rigid prosthesis, a structural evaluation under the same loading conditions has been developed and the results critically compared.

The personal characteristic biometric parameters of the patient femur-hip system have been carried out before running the structural analysis.

The 3Matic software has been used to identify the direction of the loading axis, the center of the proximal epiphysis head sphere, and the center of the joint epicondyle and mechanical axis of rotation of the knee. 
DOI: 10.14807/ijmp.v12i8.958

Namely, the following parameters have been measured: the mechanical axis between the centers of the proximal and distal epiphyses, the angle of $143.40^{\circ}$ between the femoral neck and diaphysis axes, and the divergence of $36.65^{\circ}$ between the neck axis with the axis of epicondyles.

Finally (before running the FEM structural analyses) the physiological loads and constraints have been evaluated.

As limiting bone load condition, the equilibrium mono-podalic posture has been chosen where the gluteus muscular force balances the moment of body weight force. For a body weight of $100 \mathrm{Kg}$ and accordingly to the previously defined biometric parameters, the gluteus muscular force applied to the great trochanter is about $1800 \mathrm{~N}$ and the reaction force at the joint $2740 \mathrm{~N}$. (Kumar et al., 2016, Annunziata et al., 2006).

The equilibrium condition and femur-loading scheme are illustrated in figure 9.

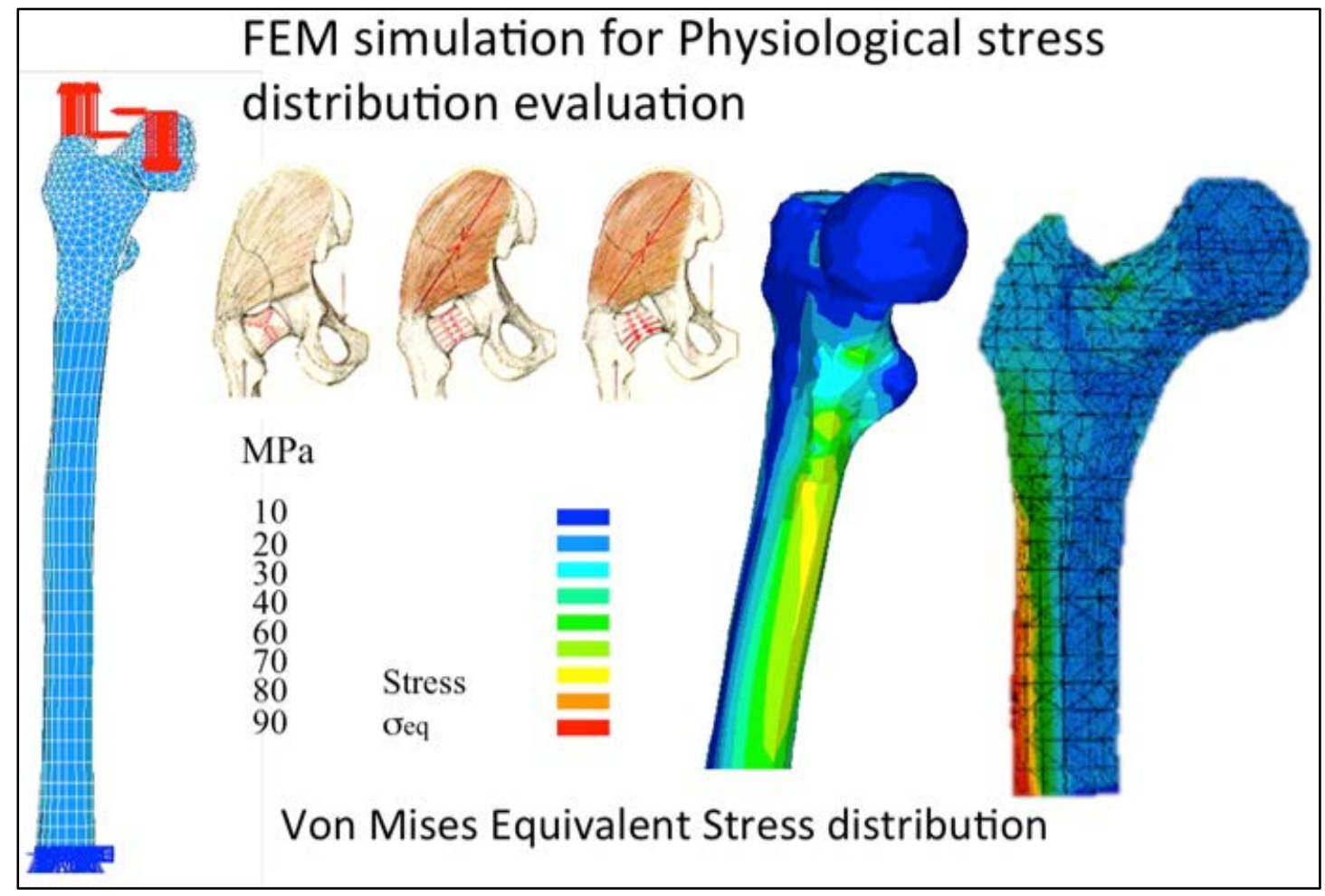

Figure 9: Phisiological Equivalent Von Mises stresses in the femur from our biofidel Finite

Element Model

Reaction forces generated by the gluteus have been uniformly distributed over 100 nodes of great trochanter surface. The reaction forces acting at the level of the femur joint are distributed on 50 nodes of the femur head (as indicated in the upper left of figure 9). 
DOI: 10.14807/ijmp.v12i8.958

\section{RESULTS AND DISCUSSION}

This study defines a biophysical model to investigate the structural behavior of the femur. The Von Mises strain criterion was used to compare stress distributions in the femur and prosthesis under the previously defined loading conditions.

This Von Mises is an energy criterion that can better quantify the capacity of the femur to withstand large tasks (right side of Figure 9).

Back, the stress distribution confirms the presence of bending effects with the highest homogeneous values distributed in the anatomical diaphysis regions (right side of figure 9), with a maximum of about $90 \mathrm{MPa}$.

The same structural analysis was performed on the FE model of the prosthetic femur described in Figures 7 and 8. The results of the analysis are compared in Figure 10 with those evaluated for the femur.

Figure 10 shows a significant change in tension distribution in the left femur (femur) and femur resected with rigid $\mathrm{Ti}$ (right) prosthesis. Compared to physiological tensions in the diaphysis of the femur, the prosthetic femur induces a concentration in the medial region, while it is completely absent in the proximal end. This event is called "stress protection effect" and is due to the high stiffness of the metal prosthesis stem that does not allow the physiological flexion of the diaphyses.

The absence of stress (and state-related condition) could induce a significant change in bone structure over time (bone reabsorption).

Bone modeling and remodeling processes, in fact, enable itself to grow, renew, and repair itself (Gottesman \& Hashin, 1980; Huiskes et al., 1987; Taylor et al., 2007; Weinans et al., 1992). Mechanical adaptation of trabecular density and architecture could be explained in terms of mechano-sensory and signaling functions for the osteocytes (Mullender \& Huiskes, 1995). The mechanic-regulation mechanism driving bone remodeling uses mechanical strain and micro-damage as the stimulus driving cellular responses and the consequent changes in the bone density and geometry. The absence or the modification of the biomechanical stimuli shown in figure 10 for the femur diaphysis after prosthesis implantation is then expected to lead, over the time, to a bone remodeling and reabsorption due to the absence of adequate stress and strain state. 
DOI: 10.14807/ijmp.v12i8.958

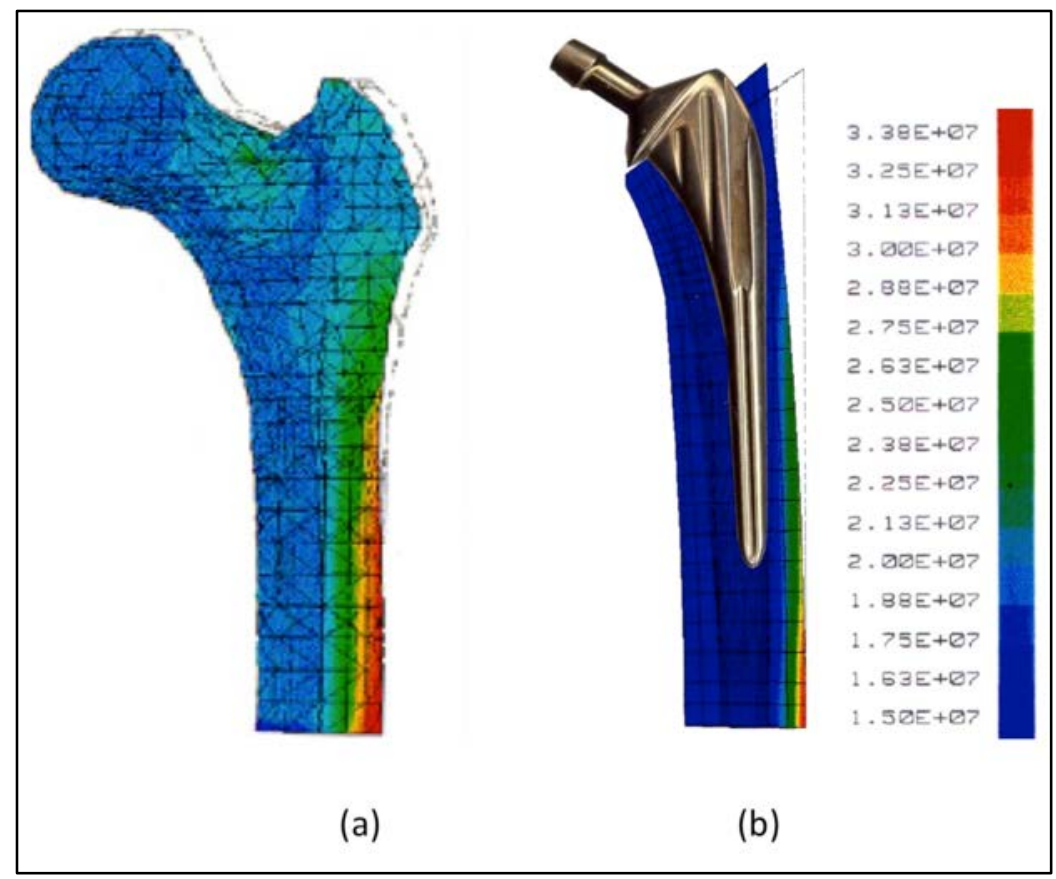

Figure 10: Equivalent Von Mises stresses distribution in the proximal femur epiphysis for (a) sound femur, (b) rigid Ti prosthesis,

Validating clinical efficacy and estimating the long-term reliability of restorative prosthetic systems require a proper understanding of the physical variables that influence the biomechanical behavior of the material for advanced biomedical applications.

The Finite Element Analysis Tool (FEA) allows biomaterials to obtain a complete assessment of the biological and mechanical behaviors of advanced restoration systems, even for non-homogeneous systems.

If validated by appropriate experimental procedures, FEA becomes useful for optimizing restoration design criteria and choosing the materials to be used. Moreover, this method allows the estimation of fracture localization in data loading circumstances (Aversa et al., 2016).

New manufacturing processes based on additive manufacturing technologies and studies on biomechanics and biomimetics (Annunziata et al., 2006; Apicella et al., 2010; Aversa et al., 2009) could allow the establishment of new design criteria for prostheses human. The authors took these studies to gather the unexploited potential of such advanced materials and design technologies by developing Biofidel Element finite models capable of mimicking correctly the biomechanical behavior of the femur (Figure 11). 
DOI: 10.14807/ijmp.v12i8.958

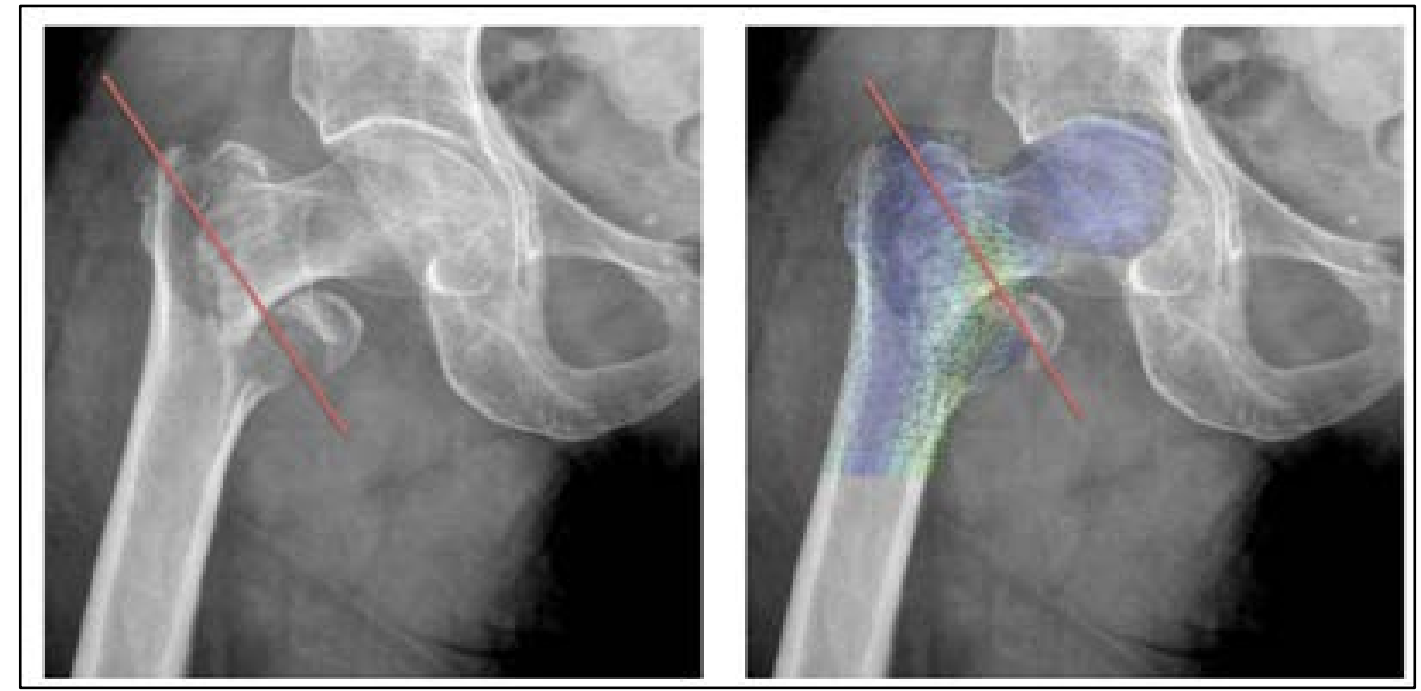

Figure 11: Fracture plane of a pertrochanteric femur fracture (left) and FEA Source: Aversa et al. (2016)

Although the human femur has an internal structure capable of withstanding high external stresses (Ashman et al., 2004), mass evolution and arrangement of cortical and trabecular bone types (Tamar \& Hashin, 1980, Oh \& Harris, 1978, 1984, Dalstra \& others, 1993). Progressive loss of physiological bone mass in the elderly or in the presence of prolonged inactivity results in bone weakness and reduced ability to withstand mechanical shocks. This reduced resistance is the main cause of pertrochanteric femoral fractures in the elderly (Ashman \& Rho, 1988; Burstein et al., 1976, Carter \& Hayes, 1977). Reducing these fractures and recovering hip joint functionality requires the application of a special prosthesis.

Currently, total hip replacement in patients less than 65 years of age and therefore longer life expectancy requiring longer durability of the orthopedic implant does not suffer for more than 15 years.

The orthopedic prostheses used today are made of metal alloys, plastics, and ceramics with well-defined properties and characteristics. In particular, due to high biocompatibility and high mechanical strength, certain metal alloys based on titanium or cobalt chromium are commonly used and represent almost all prosthetic components. These traditional prosthetic products are made from valuable technologies such as forging or melting metals, followed by mechanical machining.

These processes do not allow optimal design solutions for better biomechanical bone integration. Application of other structures on surfaces to create a more osteoinductive and osteoconductive substrate for healthy bone growth should be carried out necessarily (Schiraldi et al., 2004, Gramanzini et al., 2016). However, these processes, even if they are very 
DOI: 10.14807/ijmp.v12i8.958

expensive, do not provide sufficient structural support and are often not mechanically appropriate. Fully metallic implants, on the other hand, can allow a rapid and satisfactory structural restoration of functional mobility, while maintaining acceptable operating costs.

However, in addition to high invasiveness, these implants are not the ideal solution, especially for younger patients with long life expectancy, both in terms of duration and biomechanical osteointegration. This first generation of prostheses is technically not the optimal structure for optimal optic integration and biomechanics with bone tissue in the area around the implant.

By comparing a metal prosthesis with human bones to a radiographic examination, the density and mass difference that can induce healthy bone growth (Apicella et al., 2015) is evident.

Frost (1987) states that the adaptive properties of bones depend on the range of physiological strains to which the bone is subjected. Implantation of implants may favor reabsorption processes that lead to a greater and more unstable and unstable condition until the prosthesis shows signs of weakness, will move from its position, causing serious consequences and pain for the patient. In more severe cases, the implant breaks down, which requires immediate replacement.

Biomechanics and biomimetics: a way to promote advanced materials and advanced technologies

The implants are then expected to serve for a much longer period, without failure or surgical revision. Designing and improving suitable combinations of prosthetic materials and systems demonstrating increased resistance and enhanced biocompatibility become mandatory.

It is expected that the prosthetic bone of the resected bone will provide an "equivalent stiffness" (the combination of the elastic modulus of the material and the shape of the prosthesis) that matches that of the missing bone and the prosthesis in which it is implanted.

Due to the orthotropic density and the different density of the structure, the bone elastic modulus can vary from 4 to $20 \mathrm{GPa}$, which depends on the bone type and the loading direction. The metallic materials and ceramic implant adopted today, characterized by a greater rigidity than the bone when implanted, strongly alter the local stress of the physiological distribution of unwanted bone resorption through the implant and hence the increased risk of implant failure. 
DOI: 10.14807/ijmp.v12i8.958

This biomechanical mismatch reduces the level of biological demand for healthy bone growth (Frost, 1994) and loss of bone mass due to this reduced burden, known as stress shielding.

A personalized material with an improved combination of strength and stiffness that fits the bone should be used for biomechanical integration of the implant. This higher biomechanical compatibility will avoid loosening the implant and increase lifespan, avoiding additional surgery for review and allowing good biological integration (bone growth).

Innovative biomimetic materials for tissue engineering based on hydrophilic polymers have been developed by our research group and exhibited attractive physical, biological and mechanical properties for biomedical applications (Schiraldi et al., 2004). For use with metal prostheses, the authors developed a hybrid, highly biocompatible hybrid material based on chemical and hydrophilic (hydroxy-ethyl-methacrylate) hydrophilic materials.

The structural metal structure of the new prostheses will be made of titanium alloys using additive technology based on the melting of thin titanium powder layers (about 50 microns) on each other until the desired component is obtained. Then, nanostructured biomaterial and osteoconductive material developed in our previous studies (Schiraldi et al., 2004) can cover the titanium structural prosthetic skeleton.

These hybrid biological prostheses, which are made using synthetic materials capable of inducing the growth of biological networks and structural steel scaffolds, may favor the emergence of new classes of orthopedic hybrids in the medical field.

The new hybrid bio-prosthesis could drastically reduce stress protection while offering an advantageous improvement in the life of the prosthesis compared to traditional solutions. Recovering optimal joint functionality will improve the quality of life of the patient, which perceives a significant reduction in the risk of new surgery.

The requirement to predict the potential structural changes that may be induced by the inappropriate use of biologically compatible prostheses in bone structure and morphology forced our studies to evaluate the fictitious patterns that could be considered for real bone distribution and its orthotropic behavior (Aversa et al., 2016).

The development of loyal models has already allowed us to prepare prostheses that could restore natural stress and physiological strains in the bone (Apicella et al., 2010; Gramanzini et al., 2016; Perillo et al., 2010) 
DOI: 10.14807/ijmp.v12i8.958

In this study, a FEM femoral model was developed that was developed in a previous paper to represent the exact structural behavior of the femur head (Aversa et al., 2016) for the distribution of stress and strains throughout the stem, femoral head resection, and Titan articulated replacement. A comparison of the biologic stress and strain distribution in the femoral neck and the femoral femur could help to understand the correct design procedures needed to design new innovative biomimetic prostheses.

Segmentation of medical images was derived from CT using the Mimics software (Materialize, Belgium) to process a medical image of the patient. As shown in Figure 2, CT processing led to a solid solid solid model of the patient in the pelvis and anatomy of the femur.

New applications of prosthetic engineering through the combined use of the Mimics and 3-Matic software (Materialize, Belgium) could be derived from the biomechanical study of these bones.

A solid 3D model with finite elements (FEM) was developed in a previous work of simulating internal and external femoral morphology, as has already been done for other complex bone structures that correspond to the orientation and densities of the trabecular systems of the head (Aversa et al. 2016, Apicella et al., 2010; Beaupre \& Hayes, 1985; Reilly \& Burstein, 1974; 1975). The procedure is illustrated in figures 3-6. The outer geometry of the femur and pelvis was reconstructed by generating a three-dimensional volume that interpolates CT scans (Figure 3).

The results were then imported into 3Matic software for surface and solid surface optimization, finite element modeling, and material properties definition (Aversa et al., 2016; Apicella et al., 2010; 2015).

The results of the distribution of the material of the tetrathic element are shown in Figure 4 (the yellow corresponds to the different stiffnesses of the mechanical properties of the cortical bones, while the green ones are the trabecular bone of different densities). The same procedure was applied to the FEM model for femoral head resection, practically performed at the fractures reported in Figure 1 and for the traditional titanium prosthesis. The internal modeling of the resected femur and meta-prosthesis was accomplished by defining the threedimensional distribution of internal language optimization and language dimension, as shown in the top of Figure 5.

Massive femoral cross-links were sequentially associated with the patient's bone densities, according to the Hounsfield scale (HU). This scale quantifies the X-ray attenuation 
DOI: 10.14807/ijmp.v12i8.958

coefficients in tissues, assigning, using the Mimics software, the elastic modulus corresponding to the corresponding elements of the FEM model (bottom of Figure 5). The massive resected femoral models and the Ti prosthesis were assembled to position the implant correctly using the Mimics software.

The new mosaic of tetrarchic elements was performed in 3Matic in search of nodal congruence at the implant-bone interface.

The mechanical properties have been assigned considering the cortical and trabecular bone characteristics.

In particular, the systems have been considered as isotropic materials and the mechanical properties have been coupled with every single tethraedric element characterized by equivalent Hounsfield (HU) densities scale. The elastic and shear moduli of the trabecular bone were derived as a fraction of those of the cortical bone cortical bone with a direct proportionality with the porosity measured by the axial tomography. In this scale, the value of the fat is about-110, the muscles around 40, the trabecular bone stay between 100 and 300 while the cortical one covers the values between the high-density cortical bone (300) and about 2000, that matched in our bone systems to Elastic moduli ranging from 0,87 to 15.0 GPa.

The solid mesh elements of the trabecular-oriented material have been assigned by operating on the internal structure accounting for the real bone trabecular morphology that we found in the proximal end, (Figure 12) as indicated in Aversa et al. (2016).

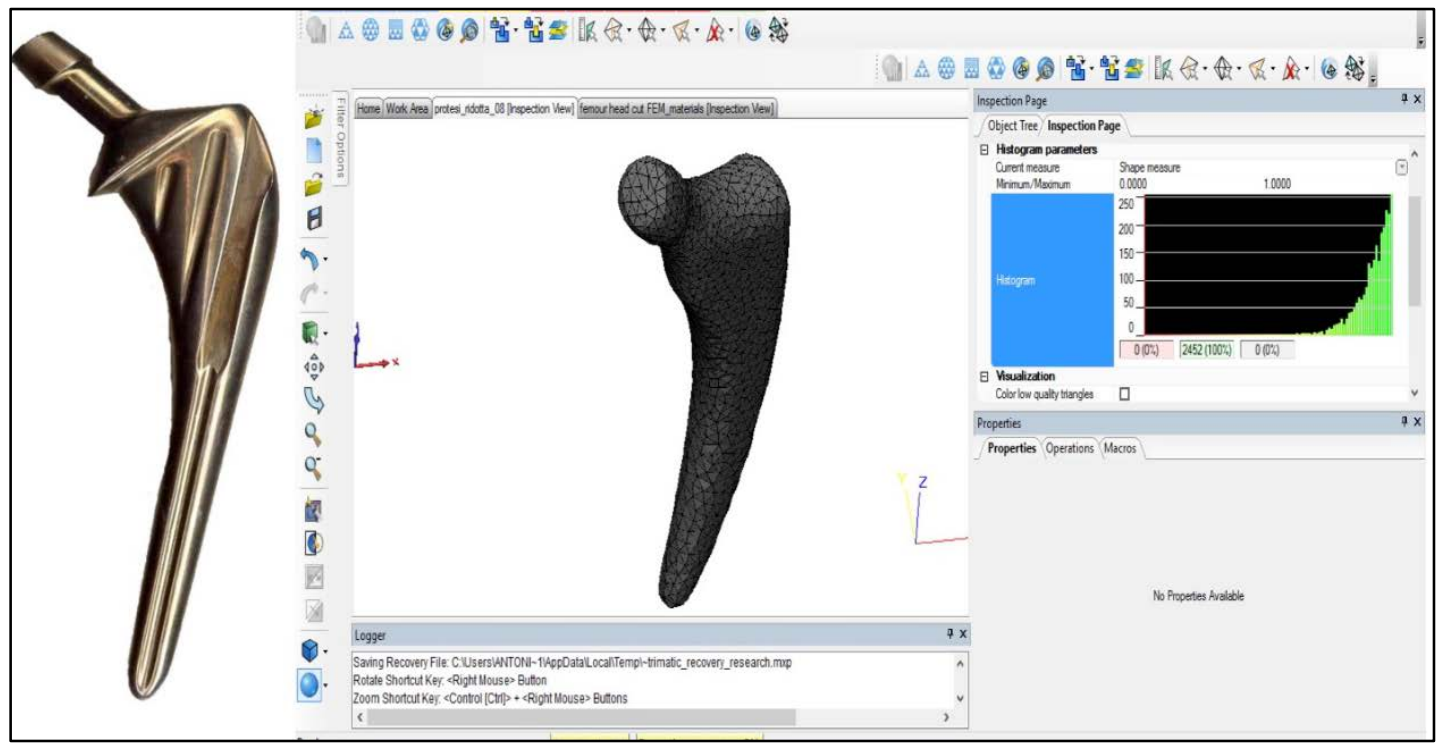

Figure 12: 3D meshing optimization of a Titanium traditional prosthesis 
DOI: 10.14807/ijmp.v12i8.958

\section{Variable Rigidity Ti Prostheses Design}

In order to avoid excessive stress shielding effects on the resected femur diaphysis (shaft), the trabecular hip joint prosthesis has been properly designed according to the characteristic and specific rigidity of each diaphysis section interested by the prosthesis.

The mechanistic model of the hip proximal epiphysis proposed by Kummer (1986) has been transferred to the hip joint prosthesis design where the presence of isostatic lines that characterizes the oriented trabecular systems, is reported in Figure 13 left-hand side).

Moreover, the biomimetic prosthesis should present rigidities along the isostatic lines that match those of the bone where it is placed.

Five regions of the prosthesis have been chosen to assign differentiated decreasing rigidities (right hand side of Figure 13).

The state stress acting on the system and the observation of the isostatic lines described by Kummer (1986) has been used to define the morphology of the porosity characterizing the trabecular structure of the stem and head of the prosthesis in different zones.

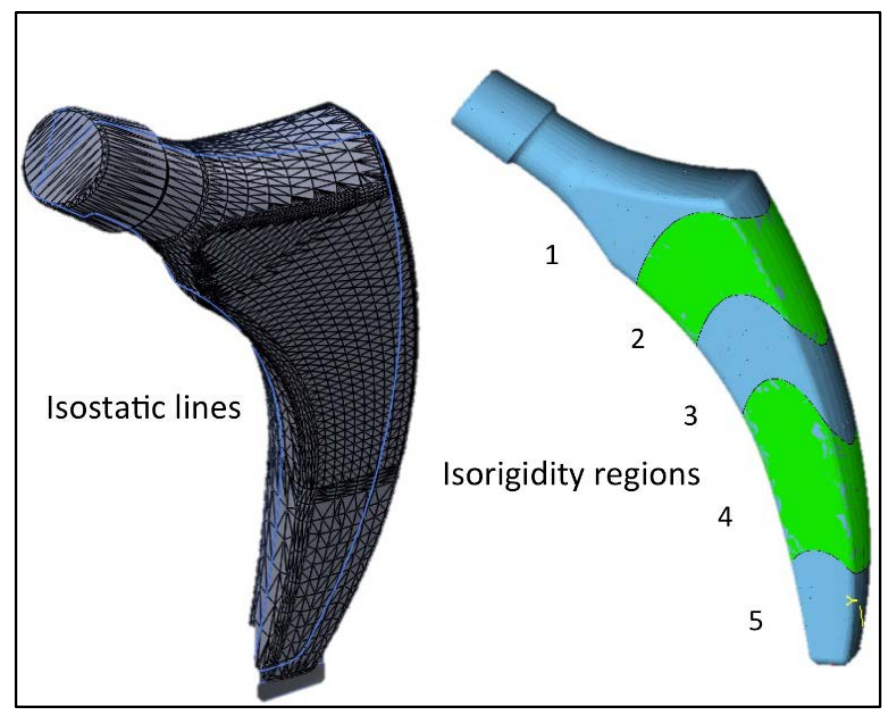

Figure 13: Left, Isostatic lines and right, Isorigidity regions chosen for the biomimetic prosthesis trabecular structure design Source: Kummer (1986) 
DOI: 10.14807/ijmp.v12i8.958

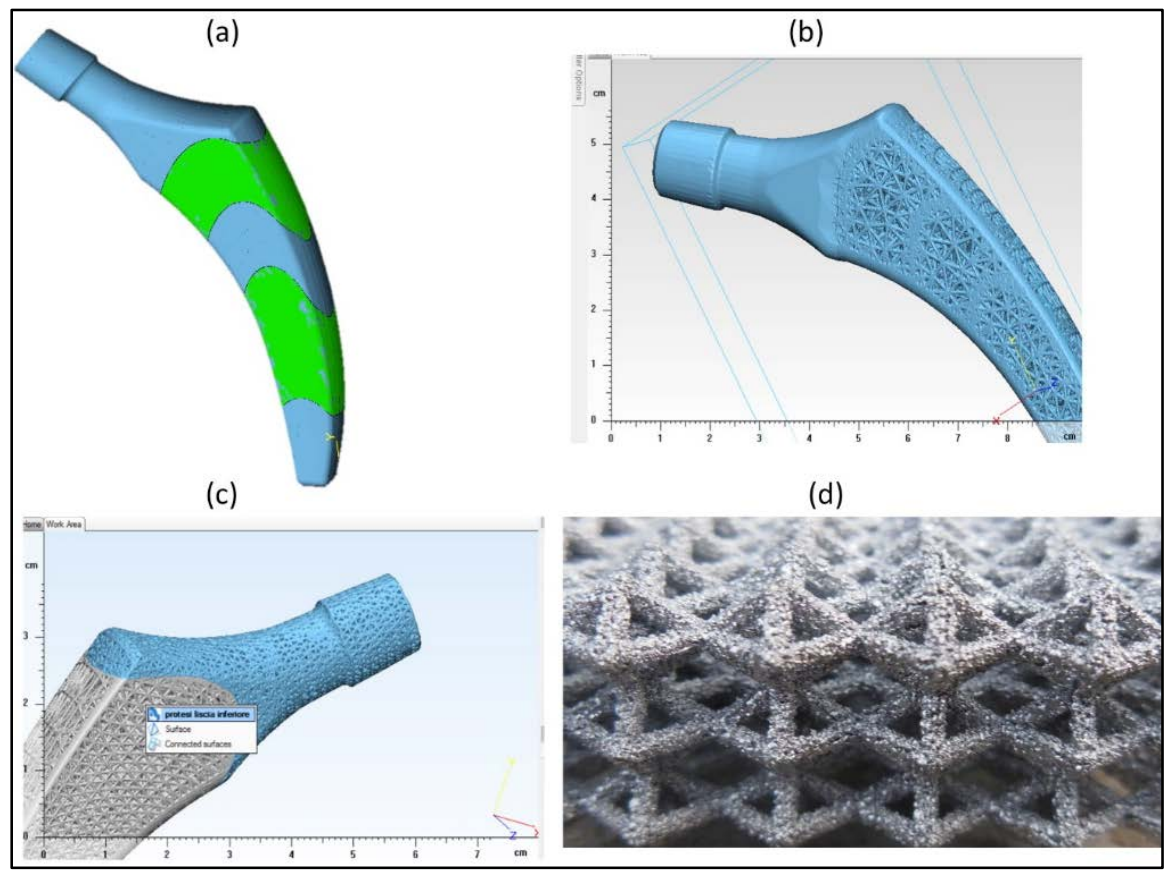

Figure 14: Flexible trabecular hip joint prosthesis with different stem and head rigidities and orientations. (a) Region of equivalent stiffness, (b) the overall flexible prosthesis, (c) internal trabecular structure, (d) Orthotropic trabecular structure obtained by additive sintering of $\mathrm{Ti}$ powders

These regions must be characterized by stiffness variations that progressively decrease from the very rigid head (region 1 of Figure 13) to extremely flexible (region 5 in Figure 13).

Isostatic lines and morphological differences of trabecular regions of iso-rigidity are better appreciated by comparing the trabecular structure of isostatic and iso-rigid regions (Figures 14b and 14c).

The orientation and different shape of the porosity of the titanium cigar are evident in the internal structure shown in Figures 10b and 10c.

An example of a trabecular iso-rigidity structure obtained by sintering the Ti alloy powder through the electron beam is shown in Figure 10d. The apparent elastic patterns of trabecular structures in the regions of iso-rigidity range from $20 \mathrm{GPa}$ for region 1 to $11,8,4$ and 1 GPa for regions 2, 3, 4 and 5, respectively.

The orientation of the trabecular system visible to the bottom left of Figure 14b seen in the area of the prosthetic stem corresponding to the femoral-tibial tibial epithelium during voltage stresses would maintain and ensure the necessary continuity of stiffness in each specific region shown in Figure 14a. Previously calculated CT values of bone densities were then linked to the isostatic lines of the cortical and trabecular bone of the femoral and femoral bone resection, taking into account each tetra-medly oriented mesh element along the isostatic stress 
DOI: 10.14807/ijmp.v12i8.958

directions observed in the proximal femoral epiphysis. Similarly, the same criterion (isostatic orientation) was used to define titanium titanium titanium titanium titanium

\section{FEM analysis: femoral teeth and tear and femoral teeth}

Based on the 3D models of the femur and femur, resected with rigid and flexible prostheses, a structural assessment was performed under the same loading conditions and the results were compared critically.

The characteristic biometric parameters of the patient's hip system were performed before the structural analysis. 3Matic software was used to identify the direction of the loading axis, the center of the proximal sphincter of the headspace and the common center of the epicondylar axis and the mechanical axis of the knee rotation.

The following parameters were measured: Mechanical axis between centers of proximal and distal epiphyses, $143.4^{\circ}$ angle between the femoral shaft and diaphysis axes and $36.65^{\circ}$ divergence between throat axis and epicondyle axis.

Finally (before the FEM structural analysis) the physiological tasks and constraints were evaluated.

\section{Loading condition and imposed constraints}

Steady-state equilibrium was considered a very serious loading condition with a rotation around the center of the hip joint when the gluteal muscle strength balances the pulse transmitted by body weight. Considering the patient's weight of $100 \mathrm{~kg}$, the gluteal muscle force applied to a large trochanter is $1800 \mathrm{~N}$ and the hip response force is $2740 \mathrm{~N}$ (these values were calculated based on the biometric data in Figure 15).

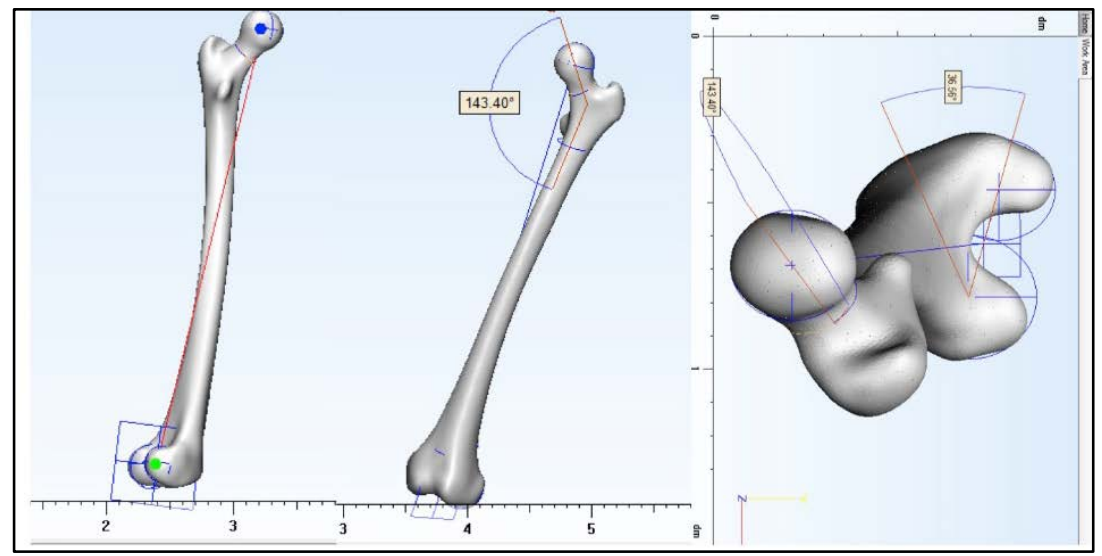

Figure 15. Biometric analysis: Mechanical axis of the femur (left); Angle of the femoral neck $\left(143.40^{\circ}\right.$, Center); Angle of divergence of the neck with the axis of epicondyles (36.65, Right)

Source: Aversa et al. (2016) 
DOI: 10.14807/ijmp.v12i8.958

The resistance of the Gluteus muscular response was evenly distributed around 100 nodes in the larger FEM trochanter, while the common hip response force was spread over 50 nodules of the femoral head (see Figure 9 above).

In this study, we defined the procedure for the preparation of a biophysical model of the femur capable of describing correctly its structural biomechanical behavior. The Von Mises strain criterion was used to compare and validate new flexible trabecular projections. Von Mises is an energy criterion that can accurately quantify the ability of bones to resist large loads (Figure 9).

The different structural behaviors of the two models are also evident in the Von Mises stress distribution, clearly different in the posterior and anterior (the right end of Figure 9 and Figure 16a). The distribution of the posterior tension confirms the presence of bending effects with the highest homogeneous values distributed in the anatomical diaphysis regions (Figure 16a).

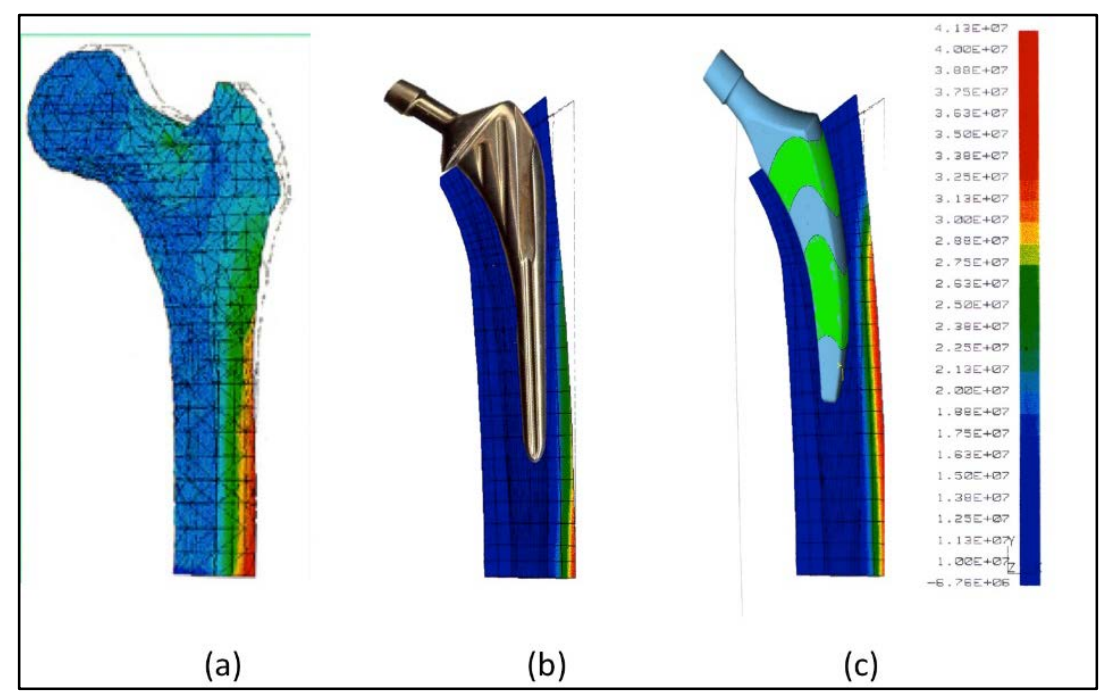

Figure 16: Equivalent Von Mises stresses distribution in the proximal femur epiphysis for (a) sound femur, (b) rigid Ti prosthesis and (c) flexible trabecular prosthesis

\section{CONCLUSIONS}

The innovative aspects of our work are that, unlike the currently used prostheses that are only intended to replace a damaged hip joint, the proposed prosthetic prostheses are capable of being completely biomimetic because they mimic the distribution of biological stress stimulates the tissue regeneration physiology.

The average life of a prosthesis today is about 10/15 years, while the new "biomimetic prosthesis" will have a higher life expectancy that can be estimated over 20/25 years. 
DOI: 10.14807/ijmp.v12i8.958

This is very important because the average length of human life increases progressively and consequently increases the number of orthopedic operations and costs related to social assistance and health.

The design and manufacture of structured personalized structured structures of innovative biomimetic systems that could be better integrated with the physiological biomechanics of the femur in which they are implanted is possible through the correct use of such biophile models.

The aim of the study is to create added value by combining existing research with biomechanical results with innovative prosthetic design and structural simulation activities.

The transfer of results into academic and industrial research on biomechanics and clinical trials leads to an acceleration of innovation and profit, while improving the quality of life of patients with prostheses.

This document identifies a set of design criteria to stimulate the potential of allowing new medical therapies to contribute to personalized healthcare, to create and improve the technology base, and to increase resource efficiency in the context of industrial and manufacturing processes. The new type of biomimetic implants can find applications in the knee, ankle, hip, shoulder and orthopedic column.

Another area of application of the product is surgical oncology to support and facilitate bone regeneration, resulting in massive losses due to primitive and metastatic tumor removal interventions.

The prosthetic system could allow for better functional recovery by promoting bone recreation to ensure good maintenance, even if it will have an impact on the quality of life of the individual patient severely compromised by the oncological pathology underlying it.

The concept of combining a support metal structure (to guarantee load resistance) a biomimetic scheme (which promotes regeneration) applies to all areas of surgical treatment involving bone removal and requires the regeneration of regenerated tissue.

\section{ACKNOWLEDGEMENT}

This text was acknowledged and appreciated by Assoc. Pro. Taher M. Abu-Lebdeh, North Carolina A and T State Univesity, United States, Samuel P. Kozaitis, Professor and Department Head at Electrical and Computer Engineering, Florida Institute of Technology, United States.

\section{FUNDING INFORMATION}


INDEPENDENT JOURNAL OF MANAGEMENT \& PRODUCTION (IJM\&P)

http://www.ijmp.jor.br

v. 12, n. 8, November-December 2021

ISSN: 2236-269X

DOI: 10.14807/ijmp.v12i8.958

This research has been funded by Italian Ministry of University and Research project FIRB Future in Research 2008 project RBFR08T83J.

\section{REFERENCES}

Annunziata, M., Aversa, R., Apicella, A., Annunziata, A., Apicella, D., Buonaiuto, C., \& Guida, L. (2006). In vitro biological response to a light-cured composite when used for cementation of composite inlays, Dental Materials, 22(12), 1081-1085. DOI: 10.1016/J.DENTAL.2005.08.009

Annunziata, M., Guida, L., Perillo, L., Aversa, R. \& Passaro, I. (2008). Biological response of human bone marrow stromal cells to sandblasted titanium nitride-coated implant surfaces. J. Mater. Sci. Mater. Med., 19, 3585-3591. DOI: 10.1007/s10856-0083514-2.

Apicella, D., Aversa, R., Ferro, E., Ianniello, D., \& Apicella, A., (2010). The importance of cortical bone orthotropicity, maximum stiffness direction and thickness on the reliability of mandible numerical models, Journal of Biomedical Materials Research - Part B Applied Biomaterials, 93(1), 150-163. doi: 10.1002/jbm.b.31569

Apicella, D., Veltri, M., Balleri, P., Apicella, A., \& Ferrari, M. (2011). Influence of abutment material on the fracture strength and failure modes of abutment-fixture assemblies when loaded in a bio-faithful simulation, Clinical Oral Implants Research, 22(2), 182-188: DOI: 10.1111/j.1600-0501.2010.01979.x

Apicella, D., Aversa, R., Tatullo, M., Simeone, M., Sayed, S., Marrelli, M., \& Apicella, A. (2015). Direct restoration modalities of fractured central maxillary incisors: A multi-levels validated finite elements analysis with in vivo strain measurements, Dental Materials, 31(12), e289-e305, DOI: 10.1016/j.dental.2015.09.016

Ashman R. B., \& Rho J. Y. (1988). Elastic modulus of trabecular bone material. J.

Biomechanics, 21, 177-181. doi:10.1016/0021-9290(88)90167-4

Ashman R. B., Cowin S. C., Van Buskirk W. C., \& Rice J. C. (1984). A continuous wave technique for the measurement of the elastic properties of cortical bone, J. Biomechanics. 17(5), 349-361. doi: 10.1016/0021-9290(84)90029-0

Aversa, R., Apicella, D., Perillo, L., Sorrentino, R., Zarone, F., Ferrari, F., \& Apicella, A. (2009). Non-linear elastic three-dimensional finite element analysis on the effect of endocrown material rigidity on alveolar bone remodeling process. Dental materials, 25, 678-690. doi: 10.1016/j.dental.2008.10.015

Aversa, R., Petrescu, F. I. T., Petrescu, R. V., \& Apicella, A. (2016a). Biomimetic FEA bone modeling for customized hybrid biological prostheses development. Am. J. Applied Sci., 13, 1060-1067. doi: 10.3844/ajassp.2016.1060.1067

Aversa, R., Parcesepe, D., Petrescu, R. V., Chen, G., Petrescu, F. I. T., Tamburrino, F., \& Apicella, A. (2016b). Glassy Amorphous Metal Injection Molded Induced Morphological Defects, Am. J. Applied Sci. 13(12), 1476-1482.

Aversa, R., Petrescu, R. V., Petrescu, F. I. T., \& Apicella, A. (2016c). Smart-Factory: Optimization and Process Control of Composite Centrifuged Pipes, Am. J. Applied Sci. 13(11), 1330-1341. 
Aversa, R., Tamburrino, F., Petrescu, R. V., Petrescu, F. I. T., Artur, M., Chen, G., \& Apicella, A. (2016d). Biomechanically Inspired Shape Memory Effect Machines Driven by Muscle like Acting NiTi Alloys, Am. J. Applied Sci. 13(11), 1264-1271.

Aversa, R., Buzea, E. M., Petrescu, R. V., Apicella, A., Neacsa, M., \& Petrescu, F. I. T. (2016e). Present a Mechatronic System Having Able to Determine the Concentration of Carotenoids, Am. J. of Eng. and Applied Sci. 9(4), 1106-1111.

Aversa, R., Petrescu, R. V., Sorrentino, R., Petrescu, F. I. T., \& Apicella, A. (2016f). Hybrid Ceramo-Polymeric Nanocomposite for Biomimetic Scaffolds Design and Preparation, Am. J. of Eng. and Applied Sci. 9(4), 1096-1105.

Aversa, R., Perrotta, V., Petrescu, R. V., Misiano, C., Petrescu, F. I. T., \& Apicella, A. (2016g). From Structural Colors to Super-Hydrophobicity and Achromatic Transparent Protective Coatings: Ion Plating Plasma Assisted TiO2 and SiO2 Nano-Film Deposition, Am. J. of Eng. and Applied Sci. 9(4), 1037-1045.

Aversa, R., Petrescu, R. V., Petrescu, F. I. T., \& Apicella, A. (2016h). Biomimetic and Evolutionary Design Driven Innovation in Sustainable Products Development, Am. J. of Eng. and Applied Sci. 9(4), 1027-1036.

Aversa, R., Petrescu, R. V., Apicella, A., \& Petrescu, F. I. T. (2016i). Mitochondria are Naturally Micro Robots - A review, Am. J. of Eng. and Applied Sci. 9(4), 991-1002.

Aversa, R., Petrescu, R. V., Apicella, A., \& Petrescu, F. I. T. (2016j). We are Addicted to Vitamins C and E-A Review, Am. J. of Eng. and Applied Sci. 9(4), 1003-1018.

Aversa, R., Petrescu, R. V., Apicella, A., \& Petrescu, F. I. T. (2016k). Physiologic Human Fluids and Swelling Behavior of Hydrophilic Biocompatible Hybrid Ceramo-Polymeric Materials, Am. J. of Eng. and Applied Sci. 9(4), 962-972.

Aversa, R., Petrescu, R. V., Apicella, A., \& Petrescu, F. I. T. (2016l). One Can Slow Down the Aging through Antioxidants, Am. J. of Eng. and Applied Sci. 9(4), 1112-1126.

Aversa, R., Petrescu, R. V., Apicella, A., \& Petrescu, F. I. T. (2016m). About Homeopathy or «Similia Similibus Curentur», Am. J. of Eng. and Applied Sci. 9(4), 1164-1172.

Aversa, R., Petrescu, R. V., Apicella, A., \& Petrescu, F. I. T. (2016n). The Basic Elements of Life's, Am. J. of Eng. and Applied Sci. 9(4), 1189-1197.

Aversa, R., Petrescu, F. I. T., Petrescu, R. V., \& Apicella, A. (2016o). Flexible Stem Trabecular Prostheses, Am. J. of Eng. and Applied Sci. 9(4), 1213-1221.

Aversa, R., Petrescu, R. V. V., Apicella, A., \& Petrescu, F. I. T. (2017). Modern Transportation and Photovoltaic Energy for Urban Ecotourism. Transylvanian Review of Administrative Sciences Special Issue, 5-20. doi: 10.24193/tras.SI2017.1

Beaupre G. S., \& Hayes W. C. (1985). Finite Element Analysis of a three dimensional opencelled model for trabecular bone. J. Biomech. Eng. 107, 249-56, PMID: 4046566

Bonfield, W., Grynpas, M. D., Tully, A. E., Bowman, J., \& Abram, J. (1981). Hydroxyapatite reinforced polyethylene - a mechanically compatible implant material for bone replacement. Biomaterials, 2, 185-186. doi: 10.1016/0142-9612(81)90050-8

Burnstein A., Reilly D. T., \& Martens M. (1976). Aging of bone tissue: Mechanical properties., J. of Bone and joint Surgery, 58, 82-86, https://www.researchgate.net/publication/21906817_Aging_of_Bone_Tissue_Mechanical_Pr operties 
Carter D. R., \& Hayes W. C. (1977). The compressive behavior of bone as a two phase porous structure. J. of Bone and joint Surgery, 59A: 954, PMID: 561786

Comerun, H. U. (1986). Six-year results with a microporous-coated metal hip prosthesis, Clin. Orthop. 20881

Čepelak I., Dodig, S., \& Čulić, O. (2013). Magnesium-more than a common cation. Med. Sci., 39, 47-68.

Chen, Q., Zhu, C., \& Thouas, G. A. (2012). Progress and challenges in biomaterials used for bone tissue engineering: Bioactive glasses and elastomeric composites. Progress. Biomater., 1, 1-22. DOI: 10.1186/2194-0517-1-2

Cormack, A. N., \& Tilocca, A. (2012). Structure and biological activity of glasses and ceramics. Philos. Trans. Math. Phys. Eng. Sci., 370, 1271-1280. DOI: 10.1098/rsta.2011.0371

Dalstyra, M., Huiskes, R., Odgaard, A., \& Van Erning, L. (1993). Mechanical and textural properties of Pelvic Trabecular Bone. J. Biomechanics, 26(4-5), 349-361, DOI: 10.1016/0021-9290(93)90014-6

Davis, P. A., Huang, S. J., Nicolais, L., \& Ambrosio, L. (1991). Modified PHEMA Hydrogels. In: Szycher M, editor. High performance biomaterials. Lancaster, PA, USA:

Technonic. 343-68.

Prashantha, K., Vasanth, K. P. K., Sherigara, B. S., \& Prasannakumar S. (2001). Interpenetrating polymer networks based on polyol modified castor oil polyurethane and poly-(2-hydroxyethylmethacrylate), synthesis, chemical, mechanical and thermal properties, bull. Mater Sci., 24(5), 535-8.

Filmon, R., Grizon, F., Baslie, M. F., \& Chappard, D. (2002). Effects of negatively charged groups (carboxymethyl) on the calcification of poly(2-hydroxyethylmethacrylate).

Biomaterials. 23, 3053-9.

Frost, H. M. (1064). Mathematical elements of lamellar bone remodeling. Springfield: Charles C Thomas. 22-25.

Frost, H. M. (1990). Structural adaptations to mechanical usage (SATMU). 2. Redifining Wolff's law: the bone remodelling problem. Anat Rec. 226, 414-22.

Frost, H. M. (2003). update of bone physiology and Wolff's law for clinicians. Angle Orthod. 74, 3-15.

Frost, H. M. (1994). Wolff's law and bone's structural adaptations to mechanical usage: an overview for clinicians. Angle Orthod. 64, 175-88.

Gramanzini, M., Gargiulo, S., Zarone, F., Megna, R., Apicella, A., Aversa, R., Salvatore, M., Mancini, M., Sorrentino, R., \& Brunetti, A., (2016). Combined microcomputed tomography, biomechanical and histomorphometric analysis of the peri-implant bone: A pilot study in minipig model. Dental Materials, 32(6), 794-806: DOI: 10.1016/j.dental.2016.03.025

Gorustovich, A. A., Roether, J. A., \& Boccaccini, A. R. (2010). Effect of bioactive glasses on angiogenesis: A review of in vitro and in vivo evidences. Tissue Eng. Part B Rev., 16, 199207. DOI: 10.1089/ten.TEB.2009.0416

Halpin J. C., \& Kardos J. L. (1976). Halpin-Tsai equations: A review, Polymer Engineering and Science, 16(5), 344-352 
Heinemann, S., Heinemann, C., Wenisch, S., Alt, V., \& Worch, H. (2013). Calcium phosphate phases integrated in silica/collagen nanocomposite xerogels enhance the bioactivity and ultimately manipulate the osteoblast/osteoclast ratio in a human co-culture model. Acta Biomaterialia, 9, 4878-4888. DOI: 10.1016/j.actbio.2012.10.010

Hench, L. L., \& Polak, J. M. (2002). Third-generation biomedical materials. Science, 295, 1014-1017. DOI: 10.1126/science.1067404

Hench, L. L., \& Thompson, I. (2010). Twenty-first century challenges for biomaterials. J. Royal Society Interface, 7, S379-S391. DOI: 10.1098/rsif.2010.0151.focus

Hench, L. L., \& Wilson, J. (1993). An introduction to bioceramics. World Sci., 1, 396-396. DOI: $10.1142 / 2028$

Hoppe, A., Güldal, N. S., \& Boccaccini, A. R. (2011). A review of the biological response to ionic dissolution products from bioactive glasses and glass-ceramics. Biomaterials, 32, 2757-2774. DOI: 10.1016/j.biomaterials.2011.01.004

Huiskes, R., Weinans, H., Grootenboer, H. J., Dalstra, M., Fudula, B., \& Slooff, T. J. (1987). Adaptive bone remodeling theory applied to prosthetic-design analysis. J Biomech. 20, 1135-1150.

Hutmacher, D.W. (2000). Scaffolds in tissue engineering bone and cartilage. Biomaterials, 21, 2529-2543. DOI: 10.1016/S0142-9612(00)00121-6

Jones, J. R., \& Clare, A. G. (2012). Bio-Glasses. An Introduction. 1st Edn., Wiley, Chichester, ISBN-10: 1118346475, 320.

Julien, M., Magne, D., Masson, M., Rolli-Derkinderen, M., \& Chassande, O. (2007). Phosphate stimulates matrix Gla protein expression in chondrocytes through the extracellular signal regulated kinase signaling pathway. Endocrinology, 148, 530-537. DOI: 10.1210/en.2006-0763

Kabra, B., Gehrke, S. H., Hwang, S. T., \& Ritschel, W. (1991). Modification of the dynamic swelling behaviour of pHEMA. J Appl Polym Sci. 42, 2409-16.

Karageorgiou, V., \& Kaplan, D. (2005). Porosity of 3D biomaterial scaffolds and osteogenesis. Biomaterials, 26, 5474-5491. doi: 10.1016/j.biomaterials.2005.02.002

Kim, H. W., Knowles, J. C., \& Kim, H. E. (2004). Development of hydroxyapatite bone scaffold for controlled drug release via poly( $€$-caprolactone) and hydroxyapatite hybrid coatings. J. Biomed. Mater. Res. Part B: Applied Biomater., 70, 240-249. DOI: 10.1002/jbm.b.30038

Kumar, A., Rathi, A., Singh, J., \& Sharma, N. K. (2016). Studies on Titanium Hip Joint Implants using Finite Element Simulation. In Proceedings of the World Congress on Engineering, 2.

Kummer, B. (1986). Biomechanical principles of the statistics of the hip joint. A critical appraisal of a new theory, Zeitschrift fur Orthopadie und Ihre Grenzgebiete, 124(2), 179187.

Mano, J. F., Sousa, R. A., Boesel, L. F., Neves, N. M., \& Reis, R. L. (2004). Bioinert, biodegradable and injectable polymeric matrix composites for hard tissue replacement: State of the art and recent developments. Composi. Sci. Technol., 64, 789-817. doi:

10.1016/j.compscitech.2003.09.001 
Mazaheri, M., Hassani, K., Karimi, A., \& Izadi, F. (2016). Finite Element Study of Composite Materials as an Alternative for Metal Hip Prothesis Using Variable Load. Materials Focus, 5(5), 430-435.

Mirsayar, M. M., \& Park, P. (2016). Modified maximum tangential stress criterion for fracture behavior of zirconia/veneer interfaces. Journal of the mechanical behavior of biomedical materials, 59, 236-240.

Mirsayar, M. M., Joneidi, V. A., Petrescu, R. V. V., Petrescu, F. I. T., \& Berto, F. (2017). Extended MTSN criterion for fracture analysis of soda lime glass, Engineering Fracture Mechanics 178, 50-59, ISSN: 0013-7944, doi: 10.1016/j.engfracmech.2017.04.018

Morales-Hernandez, D. G., Genetos, D. C., Working, D. M., Murphy, K. C., \& Leich, J. K. (2012). Ceramic identity contributes to mechanical properties and osteoblast behavior on macroporous composite scaffolds. J. Funct. Biomat., 23, 382-397. doi: 10.3390/jfb3020382

Mouriño, V., Cattalini, J. P., \& Boccaccini, A. R. (2012). Metallic ions as therapeutic agents in tissue engineering scaffolds: An overview of their biological applications and strategies for new developments. J. Royal Society Interface, 9, 401-419. doi: 10.1098/rsif.2011.0611

Montheard, J. P., Chatzopoulos, M., Chappard, D. (1992). 2-hydroxyethylmethacrylate HEMA; chemical properties and applications in biomedical fields. J Macromol Sci Macromol Rev. 32, 1-34.

Mullender, M. G., \& Huiskes, R. (1995). A proposal for the regulatory mechanism of Wolff's law. J Orthop Res.13, 503-512. doi: 10.1002/jor.1100130405

Oh, I., \& Harris W. H. (1976). Proximal distribution in the loaded femur. J. of Bone and Joint Surgery, 60-A(1) PMID: 624762

https://www.researchgate.net/publication/21906817_Aging_of_Bone_Tissue_Mechanical_Pr operties

Peluso, G., Petillo, O., Anderson, J. M., Ambrosio, M., Nicolais, L., Melone, M. A. B., Eschbach, F. O., \& Huang, S. J. (1997). The differential effects of poly(2hydroxyethylmethacrylate) and poly(2-hydroxyethylmethacrylate)/poly(caprolactone) polymers on cell proliferation and collagen synthesis by human lung fibroblasts. J Biomed Mater Res. 34, 327-36.

Perillo, L., Sorrentino, R., Apicella, D., Quaranta, A. C., Gherlone, E.D., Ferrari, M., Aversa, R., \& Apicella, A. (2010). Nonlinear visco-elastic finite element analysis of porcelain veneers: a submodelling approach to strain and stress distributions in adhesive and resin cement. The journal of adhesive dentistry, 12(5), 403-413: ISSN: 14615185

Petrescu, F. I. T., \& Calautit, K. J. (2016a). About Nano Fusion and Dynamic Fusion, Am. J. Applied Sci. 13(3), 261-266.

Petrescu, F. I. T., \& Calautit, K. J. (2016b). About the Light Dimensions, Am. J. Applied Sci. 13(3), 321-325.

Petrescu, F. L., Buzea, E., Nănuţ, L., Neacşa, M., \& Nan, C. (2015). The role of antioxidants in slowing aging of skin in a human, Analele Univers. Craiova Biologie Horticultura

Tehn. Prel. Prod. Agr. Ing. Med., 20, 567-574.

Petrescu, F. I. T., Apicella, A., Aversa, R., Petrescu, R. V., Calautit, J. K., \& Mirsayar, M. (2016a). Something about the Mechanical Moment of Inertia, Am. J. Applied Sci. 13(11), 1085-1090. 
INDEPENDENT JOURNAL OF MANAGEMENT \& PRODUCTION (IJM\&P)

http://www.ijmp.jor.br

v. 12, n. 8, November-December 2021

ISSN: 2236-269X

DOI: 10.14807/ijmp.v12i8.958

Petrescu, R. V., Aversa, R., Apicella, A., Li, S., Chen, G., Mirsayar, M., \& Petrescu, F. I. T. (2016b). Something about Electron Dimension, Am. J. Applied Sci. 13(11), 1272-1276.

Petrescu, R. V., Aversa, R., Apicella, A., Berto, F., Li, S., \& Petrescu, F. I. T. (2016c). Ecosphere Protection through Green Energy, Am. J. Applied Sci. 13(10), 1027-1032.

Petrescu, F. I. T., Apicella, A., Petrescu, R. V., Kozaitis, S. P., Bucinell, R. B., Aversa, R., \& Abu-Lebdeh, T. M. (2016d). Environmental Protection through Nuclear Energy, Am. J. Applied Sci. 13(9), 941-946.

Petrescu, R. V., Aversa, R., Apicella, A., Petrescu, F. I. T. (2016e). Future Medicine Services Robotics, Am. J. of Eng. and Applied Sci. 9(4), 1062-1087.

Petrescu, F. I. T., Petrescu, R. V., \& Mirsayar, M. M. (2017). The Computer Algorithm for Machine Equations of Classical Distribution. Journal of Materials and Engineering Structures, 4(4), 193-209. http://revue.ummto.dz/index.php/JMES/article/view/1590

Petrescu, F. I. T., Petrescu, R. V., \& Mirsayar, M. M. (2018). Inverse Kinematics to a Stewart Platform. Journal of Materials and Engineering Structures, 5(2), 111-122.

http://revue.ummto.dz/index.php/JMES/article/view/1623

Petrescu, F. I. T. (2018). Comp. Part. Mech. https://doi.org/10.1007/s40571-018-0206-7

Reilly, D., \& Burstein A. H. (1974). The mechanical properties of cortical bone. The J. Of bone and Joint Surgery, 56a(5), 1001-1021

Reilly D. T., \& Burnestain A. H. (1975). The elastic and ultimate properties of compact bone tissue. J. Biomechanics, 8, 393-405, doi:10.1016/0021-9290(75)90075-5

Rohlmann, A., Mossner, U., Bergmann, G., \& Kolbel R. (1982). Finite Element Analysis and experimental investigations of stresses in a femur. J. Biomed. Eng. 4. doi:10.1016/01415425(82)90009-7

Schiraldi, C., D’agostino, A., Oliva, A., Flamma, F., De Rosa, A., Apicella, A., Aversa, R., \& De Rosa, M. (2004). Development of hybridmaterials based on hydroxyethylmethacrylate as supports for improving cell adhesion and proliferation. Biomaterials. 25(17), 3645-3653.

Sorrentino, R., Apicella, D., Riccio, C., Gherlone, E. D., Zarone, F., Aversa, R. E., GarciaGodoy, F. F., Ferrari, M., \& Apicella, A. (2009). Nonlinear visco-elastic finite element analysis of different porcelain veneers configuration, Journal of Biomedical Materials Research - Part B Applied Biomaterials, 91(2), 727-736; doi: 10.1002/jbm.b.31449 (10)

Sorrentino, R., Aversa, R., Ferro, V., Auriemma, T., Zarone, F., Ferrari, M., Apicella, A. (2007). Three-dimensional finite element analysis of strain and stress distributions in endodontically treated maxillary central incisors restored with different post, core and crown materials. Dent Mater. 23, 983-93: doi: 10.1016/j.dental.2006.08.006

Schwartz-Dabney, C. L., \& Dechow, P. C. (2003). Variation in Cortical Material Properties Throughout the Human Dentate Mandible. American Journal of Physical Anthropology. 120, 252-277.

Tamar, G., \& Hashin, Z. V. I. (1980). Analysis of viscoelastic behavior of bones on the basis of microstructure. J. Biomechanics, 13, 89-96: DOI: http://dx.doi.org/10.1016/00219290(80)90182-7

Taylor, D., Hazenberg, J. G., \& Lee T. C. (2007). Living with cracks: Damage and repair in human bone. Nat Mater. 6, 263-268. 
ISSN: 2236-269X

DOI: 10.14807/ijmp.v12i8.958

Töyräsa, J., Lyyra-Laitinena, T., Niinimäkib, M., Lindgrenc, R., Nieminenb, M. T., Kivirantad, I., \& Jurvelina, J. S. (2001). Estimation of the Young's modulus of articular cartilage using an arthroscopic indentation instrument and ultrasonic measurement of tissue thickness. Journal of Biomechanics, 34(2), 251-256

Weinans, H., Huiskes, R., \&Grootenboer, H. J. (1992). The behavior of adaptive bone remodeling simulation models. J Biomech. 25, 1425-1441. PMID: 1491020

Wolff, J. (1892). Das Gesetz der Transformation der Knochen. Berlin: A Hirschwald. 